
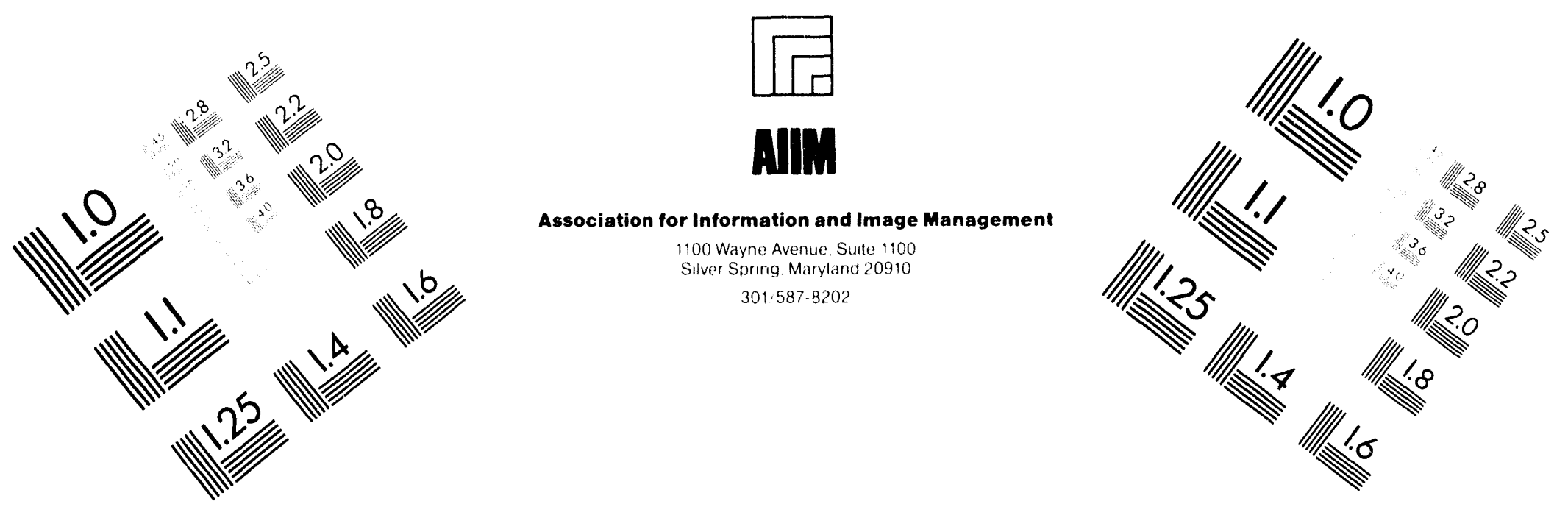

\title{
Centimeter
}

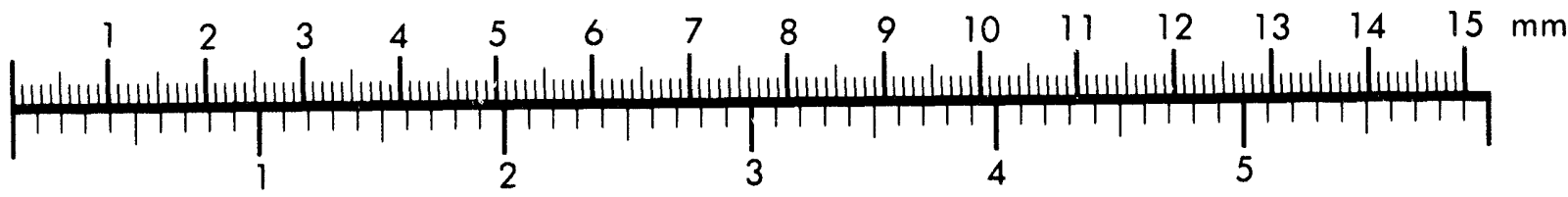

Inches
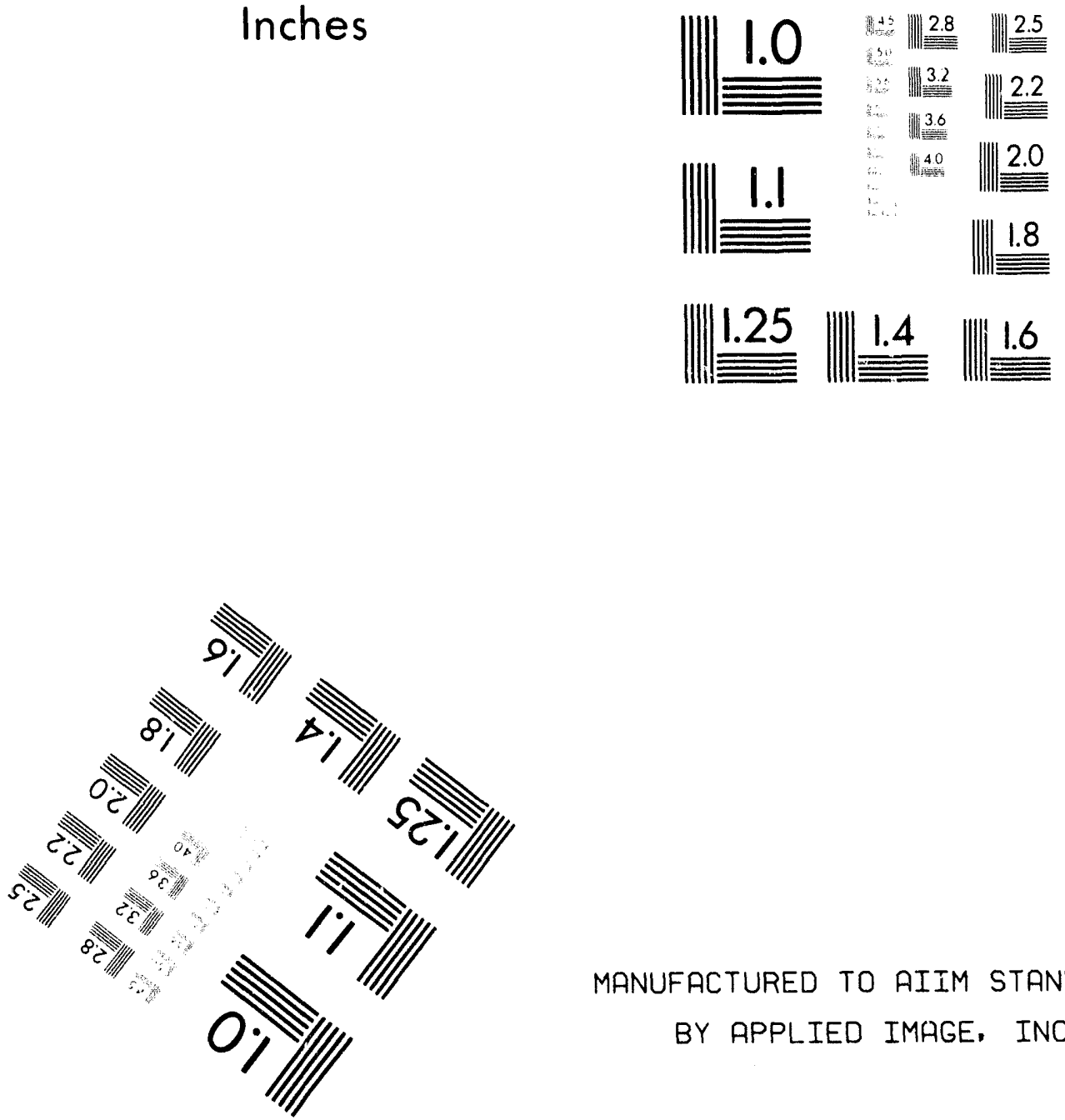

MANUFACTURED TO AIIM STANDARDS

BY APPLIED IMAGE, INC.

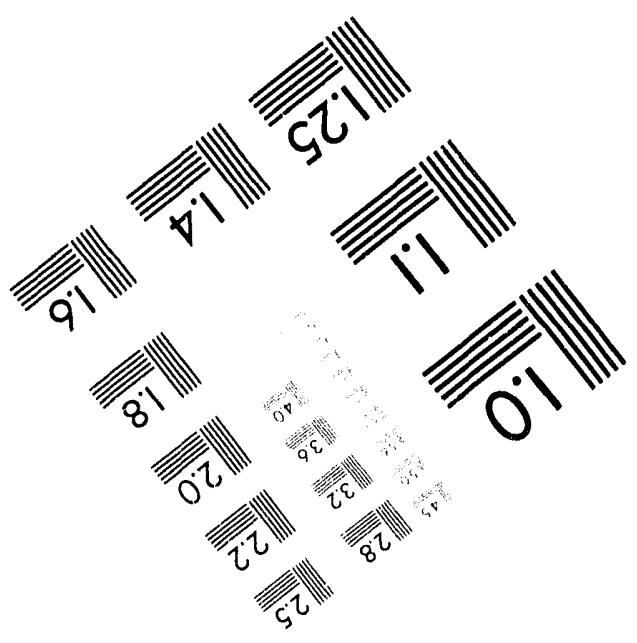



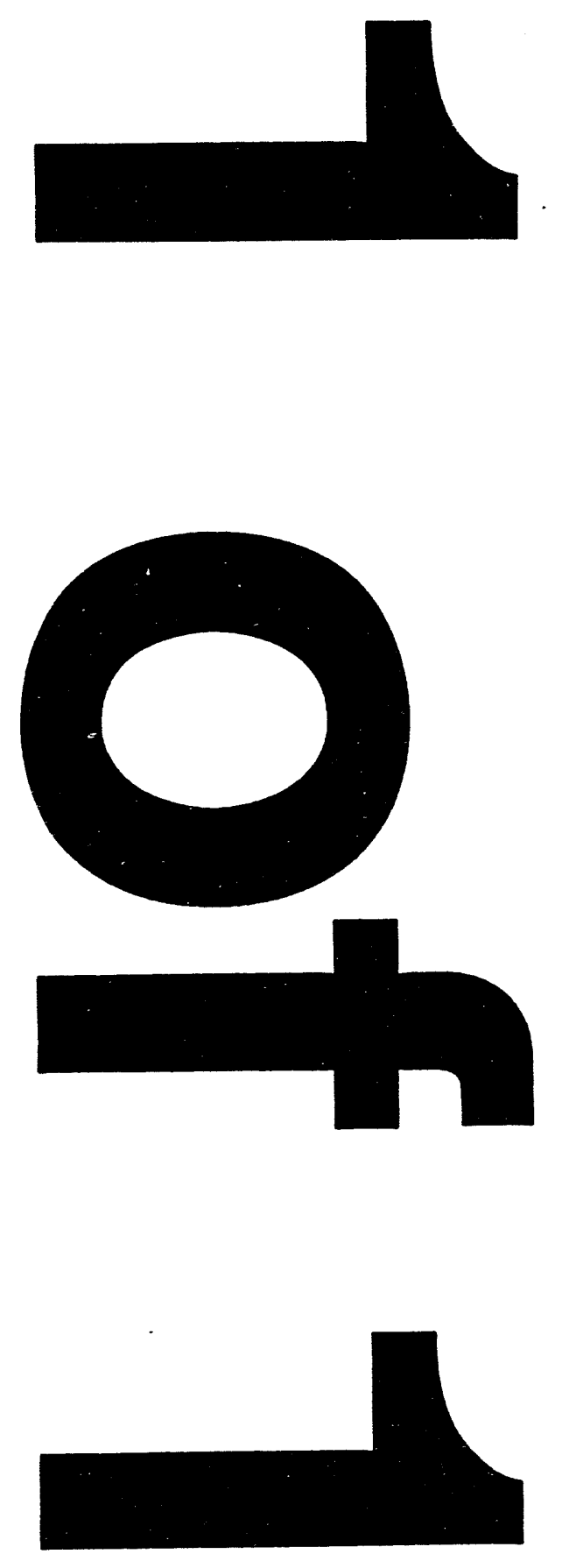


\title{
SALD- $94-8500 C$

\section{RELATIONSHIPS AMONG NITRIC OXIDE, TEMPERATURE AND MIXTURE FRACTION IN HYDROGEN JET FLAMES}

\author{
R. S. BARLOW \\ Combustion Research Facility \\ Sandia National Laboratories \\ Livermore, CA 94551-0969 \\ AND \\ C. D. CARTER \\ Systems Research Laboratories, Inc. \\ Dayton, $\mathrm{OH} 45440-3696$
}

Submitted to the Twenty-Fifth International Symposium on Combustion.

Length:

\begin{tabular}{lr} 
Text (MS Word count utility) & 2795 \\
Table 1 (12 lines) & 84 \\
Figure 1 & 700 \\
Figure 2 & 700 \\
Figure 3 & 500 \\
Figure 4 & 600 \\
Figure 5 & 200 \\
\hline Total & 5579
\end{tabular}

Preferences: $\quad$ Oral presentation,

Publication in Combustion and Flame

General Approach: (E) Experimental Data and Interpretation

Subject Codes:

(3.7) Transition and Turbulent flames (diffusion)

(3.8) Radiation Effects

(10.4) $\mathrm{NO}_{\mathrm{x}}$

Corresponding Author: Robert S. Barlow

Department 8351, MS 9051

Sandia National Labs

Livermore, CA 94551-0969

Tel: (510) 294-2688

FAX: (510) 294-1004

barlow@ca.sandia.gov

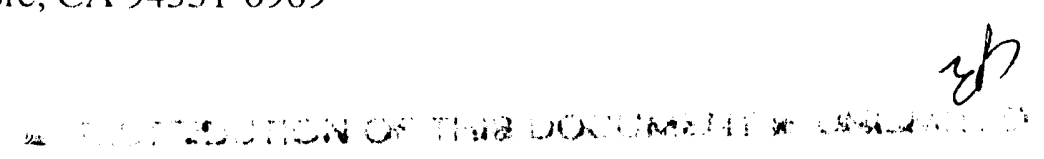




\section{ABSTRACT}

Simultaneous point measurements of NO, the major species, mixture fraction, temperature, and $\mathrm{OH}$ are obtained in nonpremixed turbulent hydrogen jet flames, using the combination of spontaneous Raman scattering, Rayleigh scattering, and laser-induced fluorescence. Results are presented for an undiluted hydrogen flame at Reynolds number 10,000 and for flames with 20 percent and 40 percent helium dilution. The radial dependence of the conditional mean NO mole fraction (conditional on mixture fraction) is shown to be small at upstream locations and negligible at the downstream locations that contribute most to the overall NO emission. Near the base of the flame, where NO formation rates and concentrations are sensitive to local strain, fluctuations of the NO mole fraction conditional on mixture fraction are 40 to 50 percent of the conditional mean. When average NO levels are calculated conditional on both mixture fraction and temperature, a significant temperature dependence is found. However, this double conditioning does not substantially reduce NO fluctuations relative to the mean values. These results combined with previously reported data on the present hydrogen flames provide a detailed basis for evaluation and refinement of turbulent combustion models for thermal $\mathrm{NO}_{\mathrm{x}}$ formation in jet flames.

\section{DISCLAIMER}

\footnotetext{
This report was prepared as an account of work sponsored by an agency of the United States
Government. Neither the United States Government employees, makes any warranty, express or implied nor any agency thereof, nor any of their bility for the accuracy, completeness, or usefulness, or assumes any legal liability or responsiprocess disclosed, or represents that its use would of any information, apparatus, product, or ence herein to any specific commercial product, process, or service by manufacturer, or otherwise does not necessarily constitute service by trade name, trademark, mendation, or favoring by the United States Governitute or imply its endorsement, recomand opinions of authors expressed herein do noternment or any agency thereof. The views United States Government or any agency thereof.
} 


\section{INTRODUCTION}

One of the critical objectives of current research and development efforts in combustion is to attain the capability to predict and minimize $\mathrm{NO}_{\mathrm{x}}$ formation in practical combustion devices [1]. A detailed knowledge of $\mathrm{NO}_{\mathrm{x}}$ formation mechanisms in simple turbulent jet diffusion flames is an important step toward this larger objective. Several experimental studies have been carried out to determine the effects of parameters such as fuel type, residence time, radiation, buoyancy, and diluents on $\mathrm{NO}_{\mathrm{x}}$ formation in jet flames [2-9]. However, these experiments were based upon gas-sampling probe techniques that yield only averaged measurements. Consequently, the details of turbulence-chemistry interactions and the instantaneous relationships between NO concentration and other scalars were not measured, and the basis for comparison with turbulent combustion models has been limited.

In the present study, pulsed-laser diagnostics are used to obtain simultaneous point measurements of $\mathrm{NO}$, major species concentrations, $\mathrm{OH}$, and temperature in turbulent hydrogen jet flames. Our initial work with this combined diagnostic capability is focused on hydrogen because its relatively simple kinetics facilitate the evaluation of combustion models, particularly with regard to the approaches used in modeling turbulence-chemistry interactions. We have made extensive measurements consisting of radial profiles at several streamwise locations in an undiluted hydrogen jet flame with a jet Reynolds number of 10,000 and in two helium diluted hydrogen flames. Dilution with helium reduces the radiation fraction to low levels, allowing for independent evaluation of turbulence/chemistry submodels and radiation submodels. A large body of results from this study were reported in Reference [10], including scatter plots of measured scalars at various streamwise locations, mean values of the NO mole fraction conditional on mixture fraction, and overall NO emission values for the undiluted and diluted flames. In the present paper we focus on the relationships among NO, mixture fraction, and temperature by considering averages and rms fluctuations of the NO mole fraction conditional on: $-\mathrm{i})$ the 
mixture fraction alone and ii) both mixture fraction and temperature. The combined results from Ref. [10] and the present paper provide an extensive basis for evaluating both the underlying assumptions and the predictive accuracy of turbulent combustion models.

\section{EXPERIMENTAL METHODS}

Experiments were conducted in the Turbulent Diffusion Flame laboratory at the Combustion Research Facility. The flow facility and diagnostic systems have been described previously [10-12], and only a brief summary is included here. Spontaneous Raman scattering was used to measure concentrations of the major species, $\mathrm{N}_{2}, \mathrm{O}_{2}, \mathrm{H}_{2}$, and $\mathrm{H}_{2} \mathrm{O}$. The Rayleigh scattering signal was converted to temperature using a speciesweighted scattering cross section, based on the Raman measurements. Linear laserinduced fluorescence (LIF) was used to measure NO and $\mathrm{OH}$. Quantitative NO and $\mathrm{OH}$ concentrations were obtained by correcting these fluorescence signals on a shot-to-shot basis for variations in the Boltzmann fraction and the collisional quenching rate, which were determined from the measured temperature and species concentrations. $\mathrm{OH}$ is a strong quencher of $\mathrm{NO}[10]$, and measured $\mathrm{OH}$ concentrations were included in the NO corrections. The NO data were also corrected for the temperature dependent effects of collisional line broadening. Mixture fraction was calculated from the measured species concentrations (moles/l) as:

$$
f=\frac{\left(w_{H 2}+\alpha w_{H e}\right)\left(\left[\mathrm{H}_{2} \mathrm{O}\right]+\left[\mathrm{H}_{2}\right]\right)+\left(w_{H}+\frac{\alpha}{2} w_{H e}\right)[\mathrm{OH}]}{w_{N^{2}}\left[\mathrm{~N}_{2}\right]+w_{O 2}\left[\mathrm{O}_{2}\right]+\left(w_{H 2 O}+\alpha w_{H e}\right)\left[\mathrm{H}_{2} \mathrm{O}\right]+\left(w_{H 2}+\alpha w_{H e}\right)\left[\mathrm{H}_{2}\right]+\left(w_{O H}+\frac{\alpha}{2} w_{H e}\right)[\mathrm{OH}]}
$$

where the w's are molecular weights, and $\alpha$ is the mole ratio of helium to hydrogen in the fuel stream. Here, the helium-hydrogen ratio is assumed to be unaffected by differential diffusion.

The burner for the turbulent hydrogen flames was a straight tube (inner diameter, $\mathrm{d}=3.75 \mathrm{~mm}$ and outer diameter $4.8 \mathrm{~mm}$ ) centered at the exit of a vertical wind tunnel contraction. The beam from a flashlamp-pumped dye laser $(532 \mathrm{~nm}, 5 \mathrm{~Hz}, \sim 750 \mathrm{~mJ} / \mathrm{pulsc}$ ) 
was used for the Raman and Rayleigh measurements. The $\mathrm{NO}$ and $\mathrm{OH}$ fluorescence measurements were accomplished using two separate Nd:YAG-pumped dye laser systems. The spatial resolution for all measurements was $-750 \mu \mathrm{m}$ in each direction.

The output of one dye laser system was tuned to the $R_{1}(18)$ transition in the $A^{2} \Sigma^{+-}$ $\mathrm{X}^{2} \Pi(0,0)$ band of NO. A solar-blind photomultiplier tube (PMT) and Schott UG-5 colored glass filters were used to collect NO fluorescence from the system of bands at 236, 247,259 , and $271 \mathrm{~nm}$. The second dye laser system was tuned to the $\mathrm{O}_{12}(8)$ transition in the $A^{2} \Sigma^{+-} X^{2} \Pi(1,0)$ band of $O H$. Colored glass filters were used in front of a PMT for broadband detection of the $(1,1)$ and $(0,0)$ bands.

The temperature dependent calibration functions for each of the Raman channels were determine by measuring signals from $\mathrm{H}_{2}$-air flat flames over a wide range of known conditions of temperature and species concentrations above a Hencken burner. (The Hencken burner is a nearly adiabatic burner consisting of an array of small fuel tubes arranged in a stainless honeycomb matrix that allows for the flow of air.) $\mathrm{OH}$ measurements were referenced to a $\mathrm{H}_{2}$-air Hencken burner flame at equivalence ratio $\phi=0.94$, where the $\mathrm{OH}$ number density was measured by laser absorption. The NO calibration factor was determined by doping lean premixed laminar flames with known concentrations of NO and differencing the signals for two doping levels. As demonstrated in Ref. [10], the sensitivity of the NO system is sufficient to obtain measurements of NO concentrations below $10 \mathrm{ppm}$.

\section{RESULTS AND DISCUSSION}

Table 1 summarizes the flow conditions and measurement locations for the experimental flames. In all cases the coflow air velocity was $1.0 \mathrm{~m} / \mathrm{s}$, and the flames were attached and unconfined. In Table $1, \mathrm{Re}$ is the cold jet exit Reynolds number, and $\mathrm{L}$ is the approximate visible flame length. These flame conditions were chosen to match, as well as possible, some of the conditions for which Driscoll et al. [9] have reported sampling-probe 
measurements of the $\mathrm{NO}_{x}$ emission index. $\mathrm{NO}_{2}$ levels within these flame are negligible 19], so the laser measurements of $\mathrm{NO}$ alone are sufficient to characterize the total $\mathrm{NO}_{\mathrm{x}}$ levels.

\section{Streamwise Evolution of Flame Structure}

Radial profiles of Favre averaged mixture fraction, temperature and NO mole fraction, $X_{N O}$, are shown in Fig. 1 for the two helium diluted flames. Corresponding profiles for the undiluted case are included in Ref. [10]. These data quantify the spreading rate of the flame and the shape of the mean stoichiometric contour. (Note that the mean mixture fraction on the centerline reaches the stoichiometric value at approximately $3 \mathrm{~L} / 4$.) Any model for $\mathrm{NO}_{\mathrm{x}}$ formation in nonpremixed flames should, at the first level, predict these mean quantities accurately, as they reflect the entrainment and mixing process and determine the global residence time for $\mathrm{NO}_{\mathrm{x}}$ formation.

The profiles for the 20 percent helium case show that, even in the mean, the mixture fraction gradient is steep near the nozzle $(x=L / 8)$, and the zones of high temperature and high NO concentration are narrow. As discussed in Ref. [10], point measurements and planar $\mathrm{OH}$ images [13] reveal a streamwise evolution of the structure of the hightemperature, NO production zone from thin layers near the flame base to broad regions near the flame tip. NO production rates near the flame base are expected to be sensitive to local scalar dissipation rates (local strain) in these thin reaction layers, due to the influence of strain on temperature depression and $\mathrm{O}$-atom superequilibrium. NO concentrations are doubly sensitive to local strain rates because of the combined effects of nonequilibrium chemistry and residence time; high local strain means low temperature and short residence time at the NO forming conditions. Further downstream $(x=3 L / 4, L)$ scalar dissipation decreases, temperature and radical concentrations approach equilibrium, the hightemperature zones become broad, and one can expect NO production rates to become more uniform. This streamwise evolution of reaction zone structure will be an important 
consideration later in this paper when we examine conditional fluctuations of NO mole fraction.

\section{Radial Dependence of the Conditional Mean $X_{N O}$}

An important assumption of the Condriional Moment Closure (CMC) model [1416] as applied to jet tlames is that the conditional mean of any scalar is independent of radial position. This has been demonstrated to be valid for major species, as long as the flame is far from extinction. However, one might expect NO to behave differently, due to the importance of convective history in the relatively slow thermal NO formation process. Figure 2 shows results for the conditional mean NO mole fraction, $\left\langle X_{N O}\right\rangle_{f}$, at various radial positions for each of six downstream locations in the undiluted flame. The curves are not smooth because we have only 6000 to 8000 samples at each streamwise position. (Operational constraints of the flashlamp-pumped dye laser made the collection of substantially more samples at each location impractical.) However, the trends are clear. In the upper part of the flame $(x=5 \mathrm{~L} / 8,3 \mathrm{~L} / 4)$ there is no significant radial dependence of the conditional mean NO mole fraction. Lower in the flame, at $\mathrm{x}=\mathrm{L} / 2$ and below, there is a small but distinct radial dependence. Five curves are shown in each plot, with the solid curve corresponding to the measurement location farthest inside the mean stoichiometric contour and the dotted curve corresponding to the location farthest outside. For fuel-rich values of the mixture fraction the solid curve is highest, while the dotted curve is highest for fuel-lean values of the mixture fraction. While this is an interesting effect, these radial variations of $\left\langle X_{N O}\right\rangle_{f}$ are minor compared to the axial variations, and we conclude that the assumption of radial independence used in the $\mathrm{CMC}$ model is reasonable for $\mathrm{NO}$, as well as for major species. Results in the diluted flames (not included here) support this conclusion. In the remainder of this paper, conditional statistics at each streamwise station are based upon data from all radial locations. 


\section{Conditional Statistics of NO Mole Fraction}

Mean and rms values of NO mole fraction conditional on mixture fraction, $\left\langle X_{N O}\right\rangle_{f}$ and $\left\langle\dot{X_{N O}}\right\rangle_{f}$, are presented in Fig. 3 for the undiluted and 20 pereent helium flames. Again, a larger number of samples would yield smoother statistics, but the data trends are nonetheless clear. In both cases the NO levels increase gradually along the length of the flame. The peak NO levels occur near the stoichiometric mixture fraction in the undiluted flame and appear to be shifted slightly to the lean side of the stoichiometric mixture fraction in the helium diluted flame. This shift may reflect the greater influence of superequilibrium O-atom concentrations on NO formation in the helium diluted case. However, systematic errors (typically under 3 percent) in mixture fraction are possible due to variations of the Raman laser line shape, and this may account for a portion of the observed shift. In both flames the conditional fluctuations of NO are quite high near the flame base, being 40 to 50 percent of the conditional mean near the stoichiometric mixture fraction at $x=L / 8$. The relative NO fluctuation, $\left\langle X_{N O}^{\prime}\right\rangle_{f} /\left\langle X_{N O}\right\rangle_{f}$, decreases as we move downstream, dropping to about 0.2 at $x=3 \mathrm{~L} / 4$ in each flame. This decrease reflects the streamwise evolution of reaction zone structure from thin layers near the nozzle to broad, near-equilibrium zones near the flame tip. Large fluctuations of scalar dissipation in the thin reaction layers cause large fluctuations in $X_{N O}$ near the flame base. Toward the flame tip, scalar dissipation and its fluctuations decrease, radical concentrations approach equilibrium, and NO production rates are expected to become more uniform. Furthermore, as fluid is convected downstream, turbulent mixing tends to average out the wide NO fluctuations that were generated near the flame base.

The highest conditional fluctuations at a given streamwise location occur near the stoichiometric mixture fraction in each case. The increase in $\left\langle X_{N O}^{\prime}\right\rangle_{f} /\left\langle X_{N O}\right\rangle_{f}$ at very lean values of mixture fraction is believed to be a measurement artifact resulting from the combination of decreased signal-to-noise at low NO concentrations and increased uncertainty in the NO fluorescence corrections at low temperatures far from the calibration 
condition. NO forms at near-stoichiometric conditions and then mixes to leaner or richer conditions as a relatively stable product. Therefore, one would expect $\left\langle X_{N O}^{\prime}\right\rangle_{f} /\left\langle X_{N O}\right\rangle_{f}$

to be greatest near the stoichiometric mixture fraction and lower elsewhere, due to the moderating influence of the mixing process.

\section{Double Conditioning on $f$ and $\mathrm{T}$}

The thermal NO production rate is extremely sensitive to temperature. Consequently, the statistical relationship between $X_{N O}$ and temperature at a given mixture fraction is of interest. Furthermore, because $\left\langle X_{N O}^{\prime}\right\rangle_{f} /\left\langle X_{N O}\right\rangle_{f}$ is so high in the upstream region of the jet flame, conditioning on mixture fraction alone may not yield adequate model predictions near the flame base. In this section we consider averages of $X_{N O}$ conditional on both mixture fraction and temperature. For each interval in mixture fraction, the mean temperature, $\langle T\rangle_{f}$, and standard deviation, $\left\langle T^{i}\right\rangle_{f}$, were calculated. Data were then sorted into five temperature bins centered at $\langle T\rangle_{f},\langle T\rangle_{f} \pm\left\langle T^{\prime}\right\rangle_{f}$, and $\langle T\rangle_{f} \pm 2\left\langle T^{\prime}\right\rangle_{f^{\prime}}$, and doubly conditional means and standard deviations, $\left\langle X_{N O}\right\rangle_{f, T}$ and $\left\langle X_{N O}^{\prime}\right\rangle_{f, T}$, were calculated.

Figure 4 includes results for three streamwise locations in the undiluted flame. For each location the upper plot shows five curves through the center values of the temperature bins, the center plot shows the corresponding $\left\langle X_{N O}\right\rangle_{f, T}$, and the lower plot shows the relative fluctuations, $\left\langle X_{N O}^{\prime}\right\rangle_{f, T} /\left\langle X_{N O}\right\rangle_{f, T}$. At $\mathrm{x}=\mathrm{L} / 8$ the spread in temperatures is greatest due to the high scalar dissipation fluctuations near the base of the flame. The corresponding values of $\left\langle X_{N O}\right\rangle_{f, T}$ vary over a wide range because of the combined effects of local scalar dissipation on temperature, $\mathrm{O}$-atom concentration, and residence time for $\mathrm{NO}$ production in the thin reaction zones. As we move downstream, temperature fluctuations decrease, bringing the temperature curves in Fig. 4 closer together. The corresponding curves of $\left\langle X_{N O}\right\rangle_{f, T}$ also move closer together, so that the relative difference between the 
highest and lowest temperature conditions is much smaller at $x=3 \mathrm{~L} / 4$ than at $x=L / 8$. We also observe that the strongest coupling between NO mole fraction and temperature occurs near stoichiometric and on the fuel-rich side, where temperatures are high and directly effect NO production rates. At fuel-lean conditions, where temperatures drop below the levels of significant NO production, the correlation between NO and temperature becomes weaker due to the moderating effect of mixing history.

At $\mathrm{x}=\mathrm{L} / 8$ the curves of $\left\langle X_{N O}^{\prime}\right\rangle_{f, T}$ are noisy because of the limited number of samples. Nevertheless, we find that the relative fluctuations at a given mixture fraction are roughly the same for each of the five temperature intervals. The level of relative fluctuations is only slightly lower than in Fig. 3 (conditional on mixture fraction alone). These observations also apply to results at $x=3 \mathrm{~L} / 8$ and $3 \mathrm{~L} / 4$.

Figure 5 gives a more direct view of the variation with temperature of $\left\langle X_{N O}\right\rangle_{f, T}$. Here, we consider only the mixture fraction interval $0.027<f<0.030$ and plot $\left\langle X_{N O}\right\rangle_{f, T}$ vs. the center values of the temperature bins. In a relative sense, the NO levels are much more sensitive to temperature near the base of the flame than near the tip. At $x=L / 8$ the NO level nearly triples between $2100 \mathrm{~K}$ and $2380 \mathrm{~K}$, while at $\mathrm{x}=3 \mathrm{~L} / 4$ there is only a roughly 20 percent increase over the same temperature range. This, again, reflects the streamwise evolution of reaction zone structure in the jet flames and the averaging effects of mixing history over the length of the flame.

\section{CONCLUSIONS}

Simultaneous point measurements of NO concentration, temperature and mixture fraction were obtained in turbulent jet flames of hydrogen and helium-diluted hydrogen. Together with results presented in Ref. [10] these multiscalar data constitute an extensive data base for the evaluation of predictive models for thermal $\mathrm{NO}_{\mathrm{x}}$ formation in nonpremixed jet flames. The following conclusions are drawn from results presented here: 
1. The radial dependence of mean NO mole fraction conditional on mixture fraction is small, particularly at downstream locations. For the purpose of modeling jet flames, it is reasonable to assume that the conditional mean NO mole fraction is independent of radius.

2. The conditional mean NO mole fraction peaks near the stoichiometric mixture fraction, and there is a gradual increase in NO levels with increasing downstream distance in all flames considered.

3. Conditional fluctuations of $\mathrm{NO}$ mole fraction are as high as 50 percent of the conditional mean near the flame base $(x=L / 8)$ and drop to roughly 20 percent of the conditional mean near the flame tip. This is attributed to the streamwise evolution of reaction zone structure from thin strained layers near the flame base to broad, nearequilibrium zones near the flame tip.

4. Double conditioning on both mixture fraction and temperature shows that the correlation between NO and local instantaneous temperature is strongest near the base of the flame, where NO production rates are most sensitive to local scalar dissipation. Double conditioning does not substantially reduce relative fluctuations of NO.

\section{Acknowledgments}

This research was supported by the United States Department of Energy, Office of Basic Energy Sciences, Division of Chemical Sciences.

\section{REFERENCES}

1. Correa, S. M., Comb. Sci Tech., 87, 329-362 (1992).

2. Kent, S. H. and Bilger, R. W., Fifteenth Symposium (International) on Combustion, The Combustion Institute, Pittsburgh, 1974, p. 1643.

3. Lavoie, G. A. and Schlader, A. F., Comb. Sci Tech., 8, 215-224 (1974). 
4. Bilger, R. W. and Beck, R. E., Sixteenth Symposium (International) on Combustion, The Combustion Institute, Pittsburgh, 1976, p. 541.

5. Drake, M. C., Correa, S. M., Pitz, R. W., Shyy, W., and Fenimore, C. P., Combust. Flame, 69, 347-365 (1987).

6. Vranos, A., Knight, B. A., Procia, W. M., Chiapetta, L., Twenty-Fourth Symposium (International) on Combustion, The Combustion Institute, Pittsburgh, p. $377,1992$.

7. Turns, S. R. and Lovett, J. A., Comb. Sci Tech., 66, 233-249 (1989).

8. Turns, S. R. and Myhr, F. H., Combust. Flame, 87, 319-335 (1991).

9. Driscoll, J. F., Chen, R.-H., Yoon, Y., Combust. Flame, 88, 37-49 (1992).

10. Barlow, R. S. and Carter, C. D., "Raman/Rayleigh/LIF Measurements of Nitric Oxide Formation in Turbulent Hydrogen Jet Flames," Combust. Flame, (to appear).

11. Barlow, R. S., Dibble, R. W., Chen, J.-Y., and Lucht, R. P., Combust. Flame, 82, $235-251(1990)$

12. Carter, C. D. and Barlow, R. S., "Simultancous Measurements of NO, OH, and the Major Species in Turbulent Flames," Optics Letters, (to appear).

13. Seitzman, J. M., Üngüt, A., Paul, P. H., and Hanson, R. K., Twenty-Third Symposium (International) on Combustion, The Combustion Institute, Pittsburgh, 1990, p. 637.

14. Bilger, R. W. Phys. Fluids A, 5, 436-444 (1993).

15. Klimenko, A. Yu., Fluid Dynamics, 25, 327-334 (1990).

16. Smith, N. S. A., Bilger, R. W., Chen, J.-Y., Twenty-Fourth Symposium (International) on Combustion, The Combustion Institute, Pittsburgh, 1992, p. 263. 
Table 1 Flame Parameters and Measurements Locations

\begin{tabular}{cccc}
$\begin{array}{c}\mathrm{H}_{2}: \mathrm{He} \\
\text { (by vol.) }\end{array}$ & $\mathrm{Re}$ & $\begin{array}{c}\mathrm{L} / \mathrm{d} \\
\text { (visible) }\end{array}$ & $\begin{array}{c}\text { Streamwise } \\
\text { Locations }(\mathrm{x} / \mathrm{L})\end{array}$ \\
\hline $100: 0$ & 10,000 & $\sim 180$ & $\begin{array}{c}1 / 8,1 / 4,3 / 8, \\
1 / 2,5 / 8,3 / 4,1\end{array}$ \\
$80: 20$ & 10,000 & $\sim 150$ & $\begin{array}{c}1 / 8,1 / 4,3 / 8, \\
1 / 2,5 / 8,3 / 4,1\end{array}$ \\
$60: 40$ & 9,300 & $\sim 100$ & $1 / 2,3 / 4,1$ \\
\hline
\end{tabular}




\section{Figure Captions}

Fig. 1. Radial profiles of Favre average mixture fraction, temperature and NO mole fraction in the helium diluted flames. Visible flame lengths for the 20 and 40 percent helium cases are $\mathrm{L}=150 d$ and $\mathrm{L}=100 d$, respectively. Streamwise locations are: $O \mathrm{~L} / 8$; $\square \mathrm{L} / 4 ; \diamond 3 \mathrm{~L} / 8 ; \Delta \mathrm{L} / 2 ; \mathrm{LL} / 8 ; \mathbf{L} \mathrm{L} / 4 ; \Delta \mathrm{L}$.

Fig. 2. Conditional mean NO mole fractions calculated for each five radial positions at six streamwise stations in the undiluted $\mathrm{H}_{2}$ flame. In each plot the progression of line types (- $),(---),(---\infty),(-\ldots-\ldots),(\ldots . . .$.$) runs from a radial location on the rich side$ of the mean stoichiometric contour to a radial location on the lean side.

Fig. 3. Mean values and relative fluctuations of NO mole fraction conditional on mixture fraction in the undiluted and 20 percent helium cases. Visible flame lengths $\mathrm{L}$ are $180 \mathrm{~d}$ and 150d, respectively. Streamwise locations are: $\bigcirc \mathrm{L} / 8 ; \square \mathrm{L} / 4 ; \diamond 3 \mathrm{~L} / 8 ; \Delta \mathrm{L} / 2 ; \bigcirc 5 \mathrm{~L} / 8$; $3 \mathrm{~L} / 4 ; \Delta \mathrm{L}$.

Fig. 4. Results for mean NO mole fraction and relative fluctuations conditional on both temperature and mixture fraction at three streamwise stations in the undiluted $\mathrm{H}_{2}$ flame. Line types correspond to the five conditional temperatures defined by:

$$
\begin{aligned}
& (-)\langle T\rangle_{f}+2\left\langle T^{\prime}\right\rangle_{f},(---)\langle T\rangle_{f}+\left\langle T^{\prime}\right\rangle_{f},(-\cdots--)\langle T\rangle_{f},(-\ldots)\langle T\rangle_{f}-\left\langle T^{\prime}\right\rangle_{f}, \\
& (\ldots \ldots)\langle T\rangle_{f}-2\left\langle T^{\prime}\right\rangle_{f} .
\end{aligned}
$$

Fig. 5. Doubly conditional mean values of $\mathrm{NO}$ mole fraction plotted against temperature for the mixture fraction interval $0.027<f<0.030$ for the undiluted flame. Streamwise locations are: $O \mathrm{~L} / 8 ; \diamond 3 \mathrm{~L} / 8$; and $\mathbf{D} 3 \mathrm{~L} / 4$. 

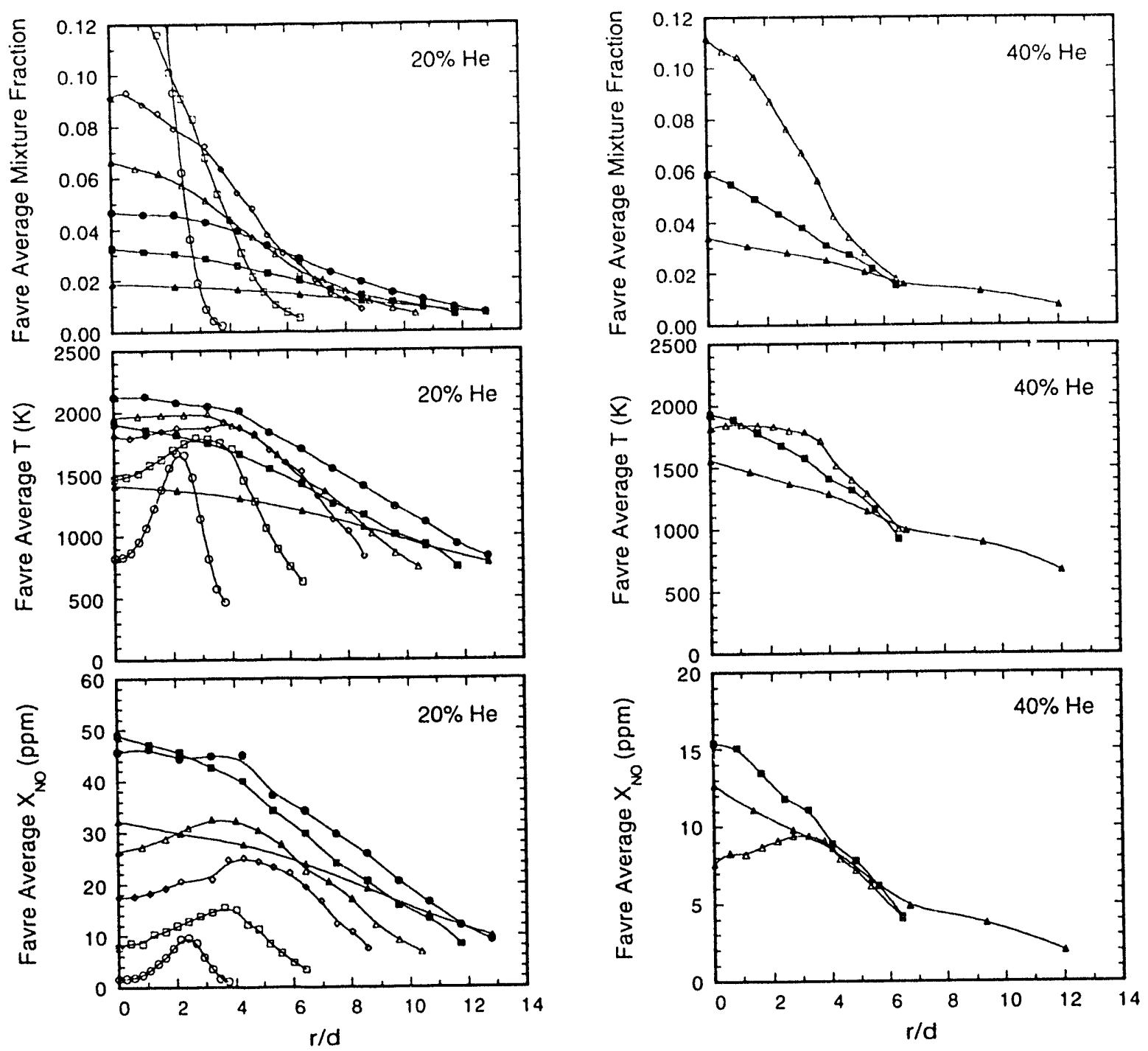

Fig. 1. Radial profiles of Favre average mixture fraction, temperature and NO mole fraction in the helium diluted flames. Visible flame lengths for the 20 and 40 percent helium cases are $\mathrm{L}=150 d$ and $\mathrm{L}=100 d$, respectively. Streamwise locations are: $\mathrm{O} L / 8$;

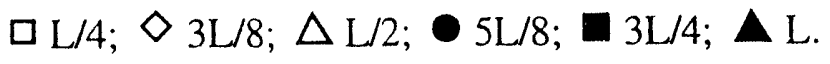



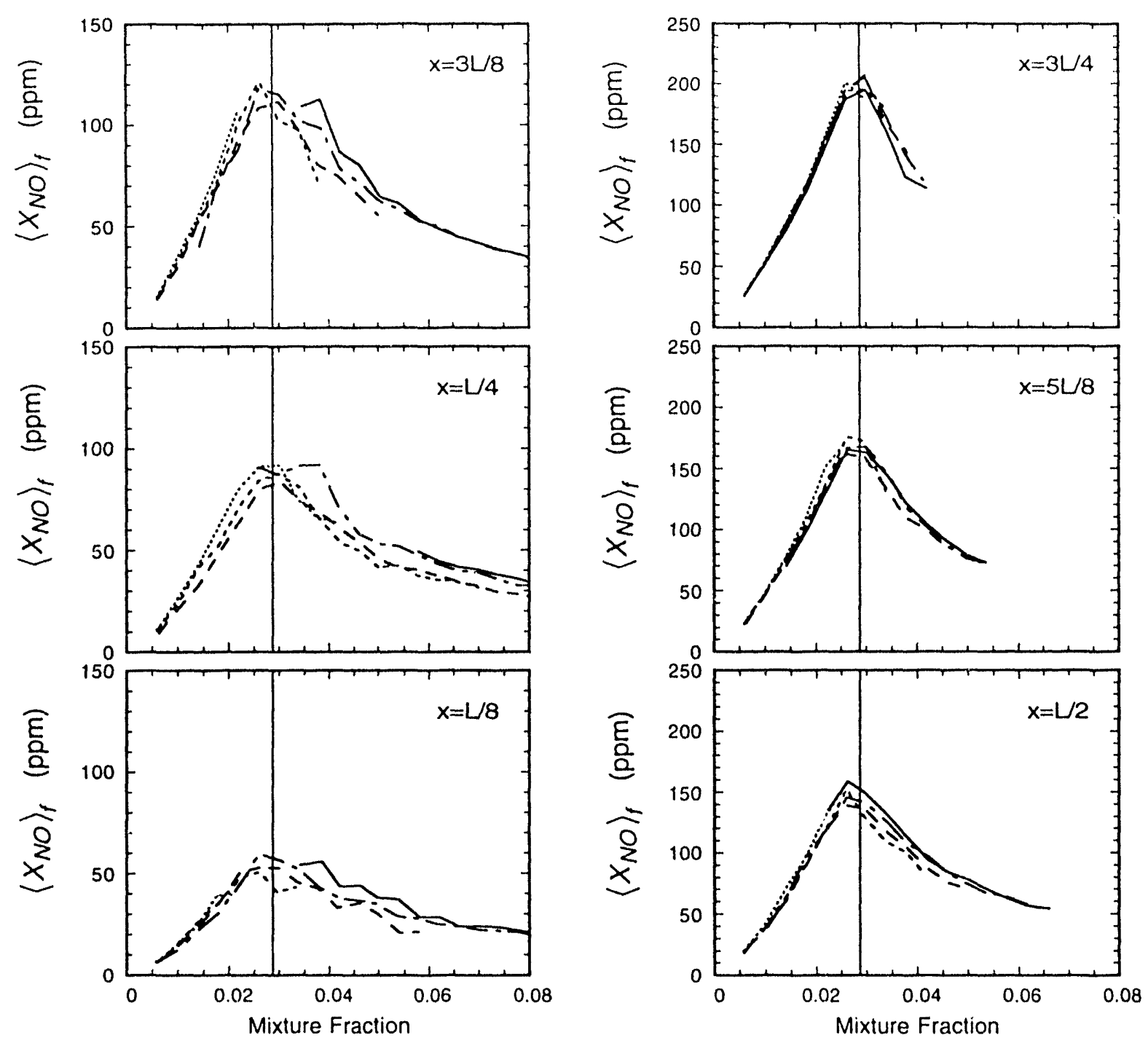

Fig. 2. Conditional mean NO mole fractions calculated for each five radial positions at six streamwise stations in the undiluted $\mathrm{H}_{2}$ flame. In each plot the progression of line types ( $-(--\ldots),(---\infty),(-\ldots--),(\ldots . .$.$) runs from a radial location on the rich side$ of the mean stoichiometric contour to a radial location on the lean side. 

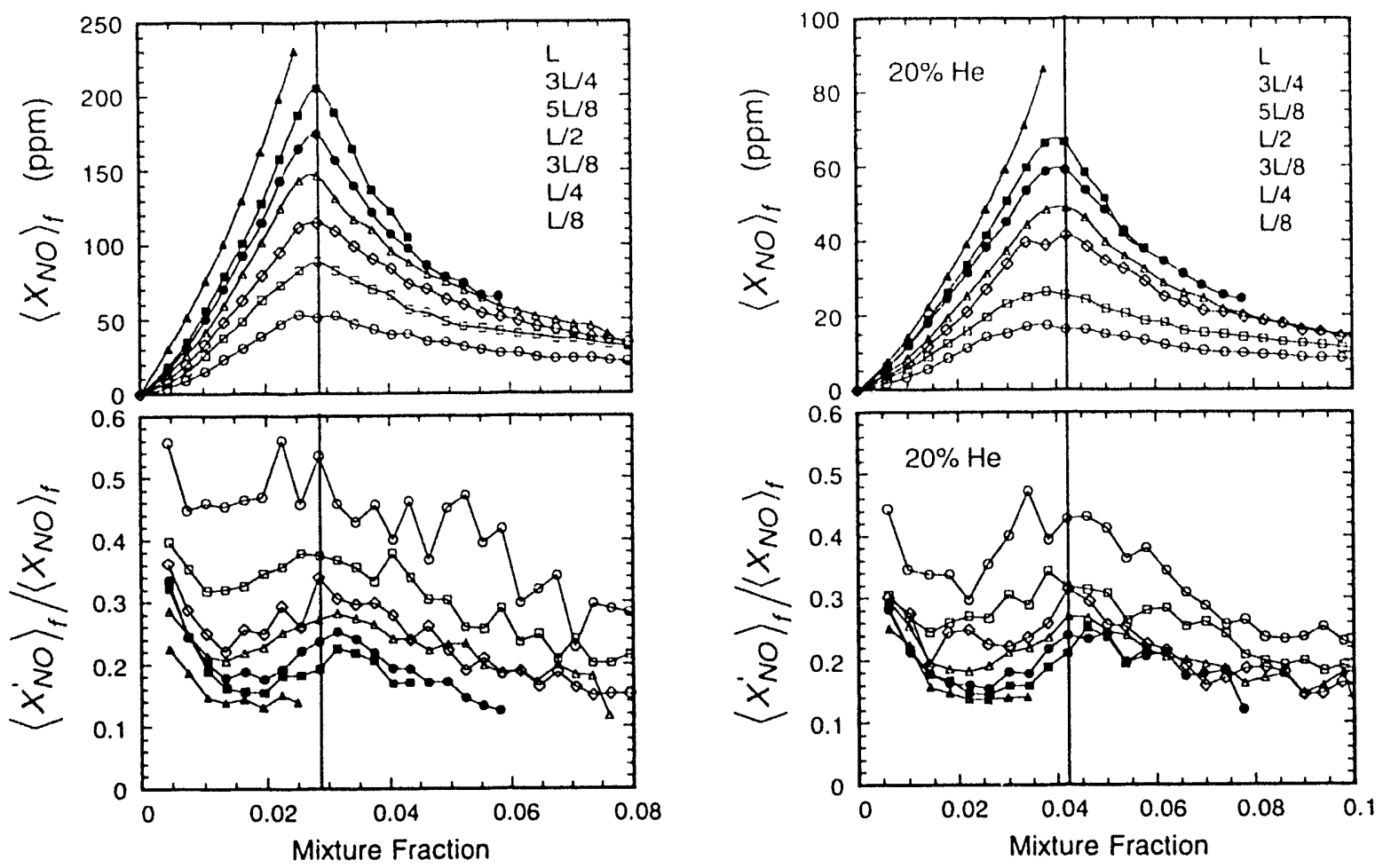

Fig. 3. Mean values and relative fluctuations of NO mole fraction conditional on mixture fraction in the undiluted and 20 percent helium cases. Visible flame lengths $\mathrm{L}$ are $180 d$ and $150 d$, respectively. Streamwise locations are: $\bigcirc \mathrm{L} / 8 ; \square \mathrm{L} / 4 ; \diamond 3 \mathrm{~L} / 8 ; \Delta \mathrm{L} / 2 ; \bigcirc 5 \mathrm{~L} / 8$; $3 \mathrm{~L} / 4 ; \Delta \mathrm{L}$. 

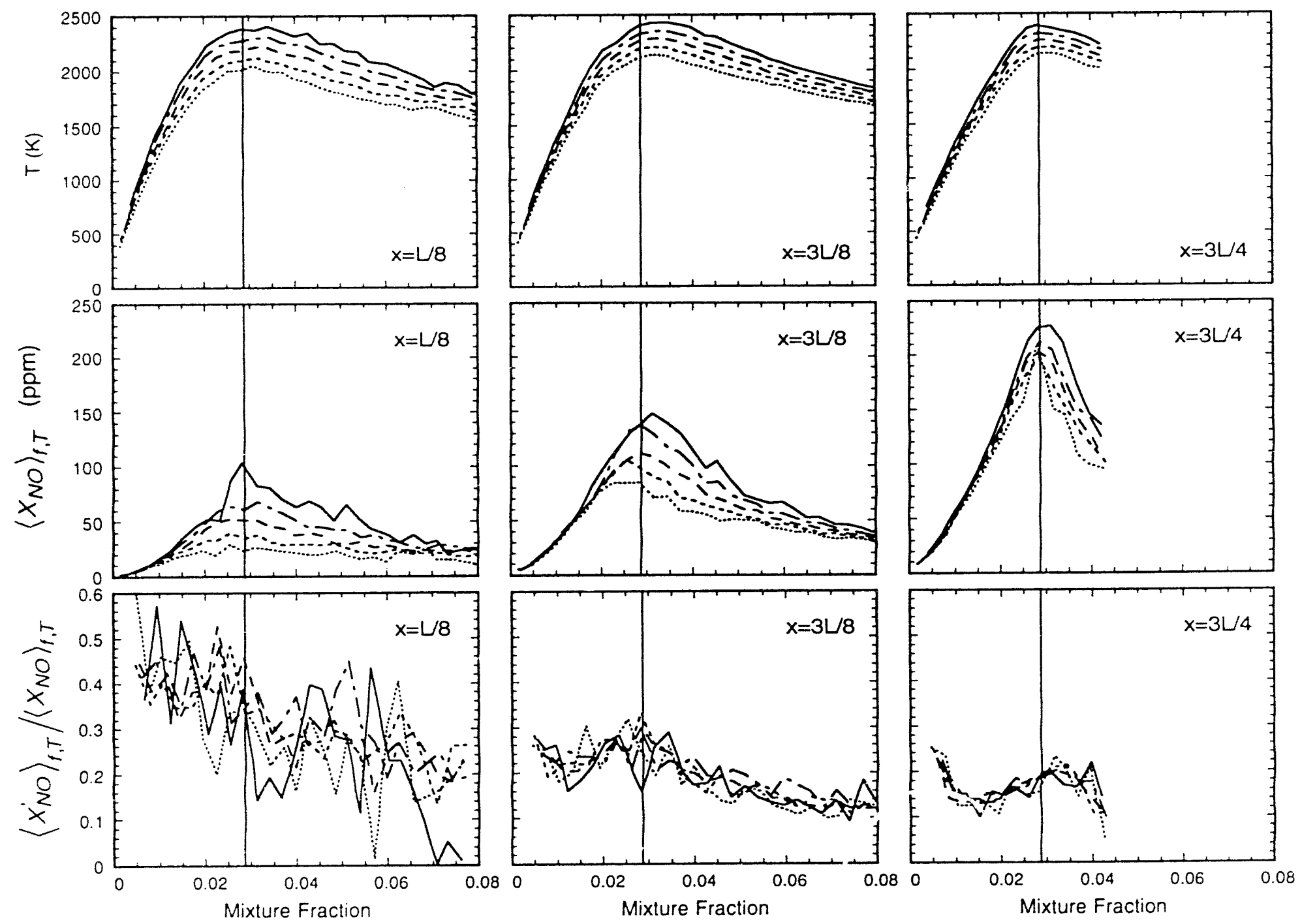

Fig. 4. Results for mean NO mole fraction and relative fluctuations conditional on both temperature and mixture fraction at three streamwise stations in the undiluted $\mathrm{H}_{2}$ flame. Line types correspond to the five conditional temperatures defined by:
$\left(\longrightarrow\langle T\rangle_{f}+2\left\langle T^{\circ}\right\rangle_{f}\right.$
$\langle T\rangle_{f}+\left\langle T^{\prime}\right\rangle_{f}$
$\langle T\rangle_{f},(-\ldots--)\langle($
$\langle T\rangle_{f}-\left\langle T^{\prime}\right\rangle_{f}$
$(\ldots . ..)\langle T\rangle_{f}-2\left\langle T^{\prime}\right\rangle_{f}$. 


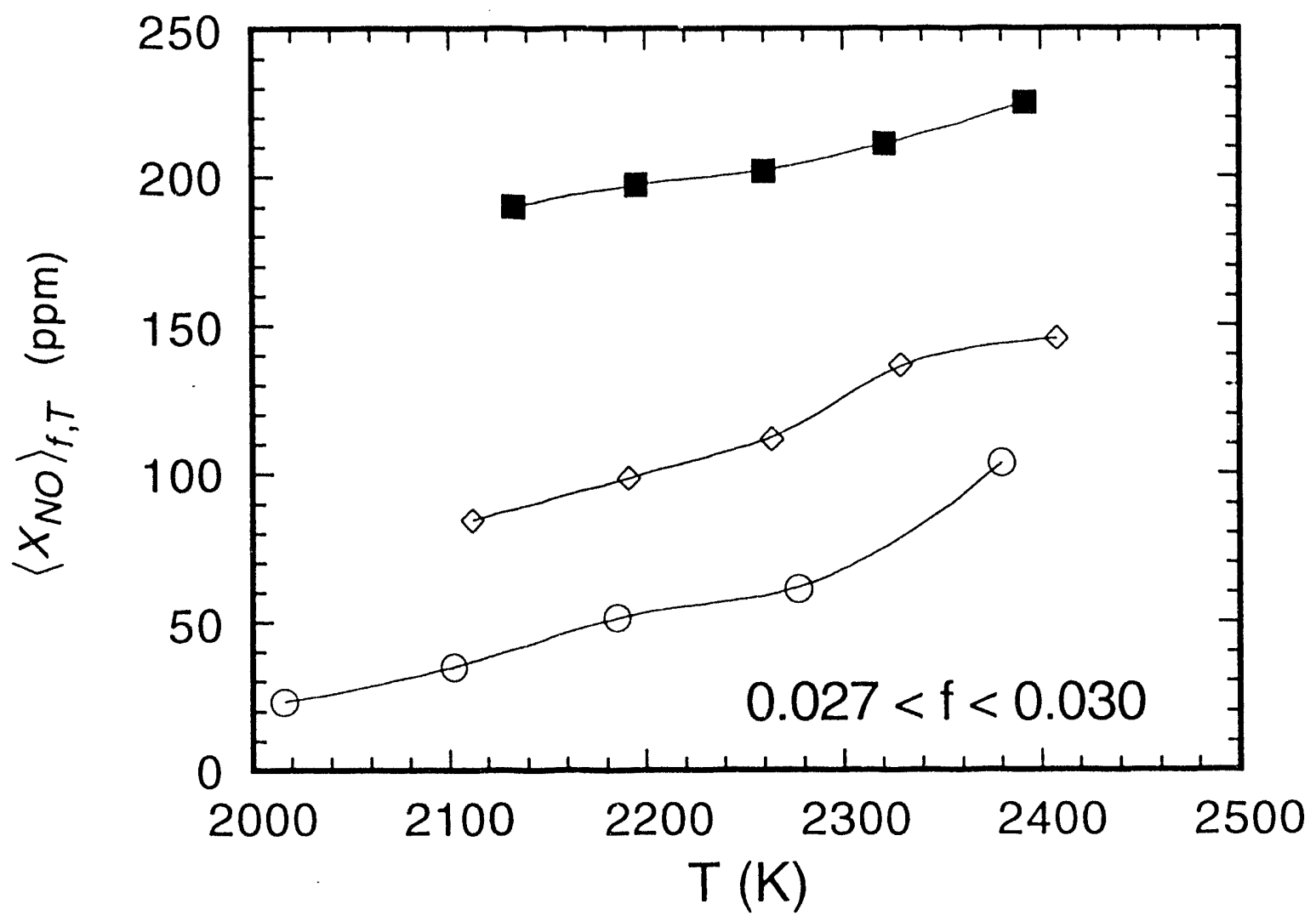

Fig. 5. Doubly conditional mean values of $\mathrm{NO}$ mole fraction plotted against temperature for the mixture fraction interval $0.027<f<0.030$ for the undiluted flame. Streamwise locations are: $\mathrm{OL} / 8 ; \diamond 3 \mathrm{~L} / 8$; and $\mathbf{\square} \mathrm{L} / 4$. 

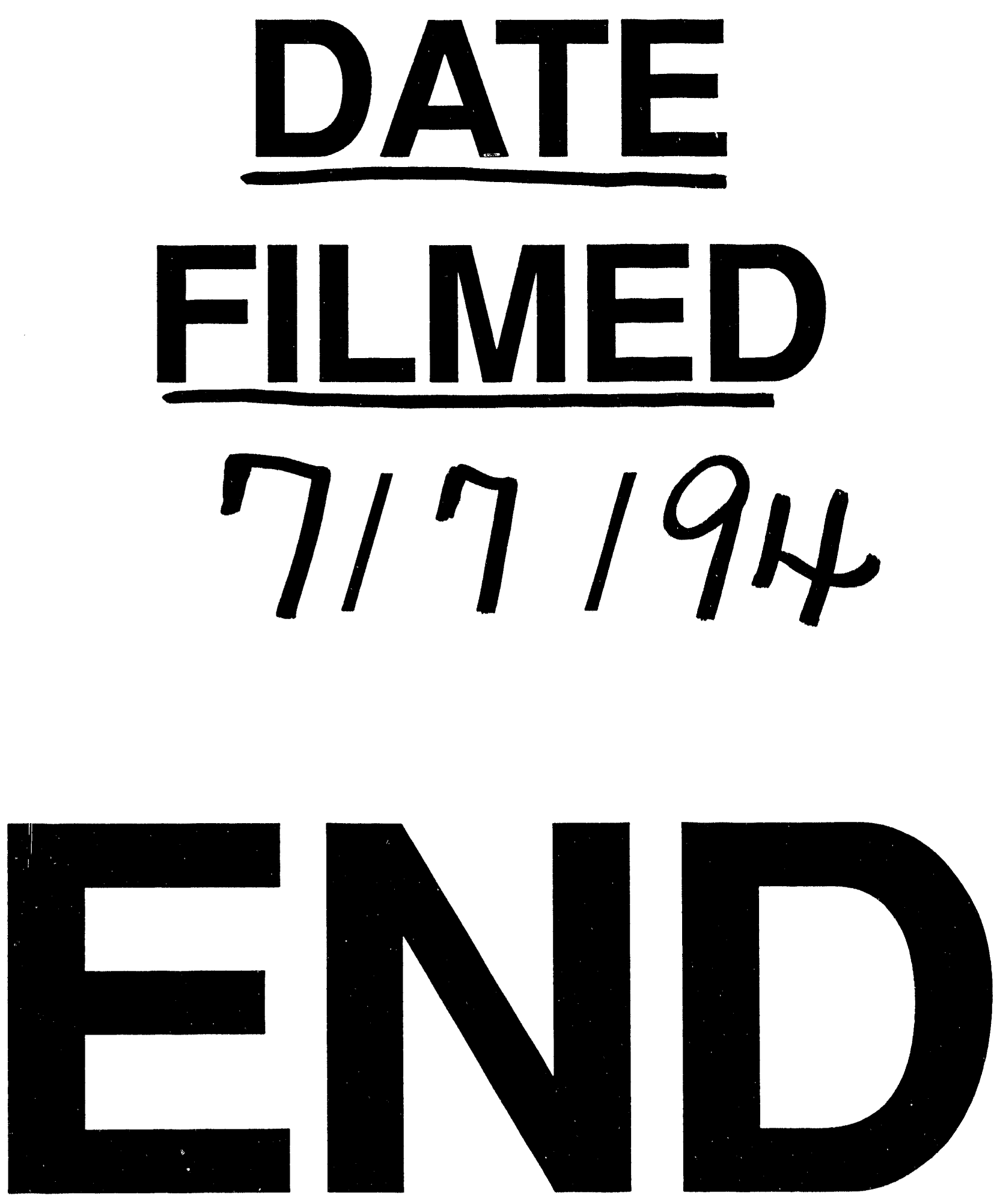


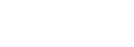

